\title{
Vertical Bipartition of the Right Anterior Section by Extraglissonian Approach
}

\author{
Ionel Câmpeanu ${ }^{1}$, Irinel Popescu², Liviu Mosoia ${ }^{3}$, Florin Botea ${ }^{2}$
}

Corresponding author:

Ionel Campeanu, MD, PhD

E-mail: ionel.campeanu@yahoo.com

Received: 20.03.2020

Accepted: 24.04 .2020

$\overline{\text { Copyright } \odot \text { Celsius Publishing House }}$ www.sgo-iasgo.com

\author{
1"Dr. Carol Davila" University of Medicine and Pharmacy Bucharest, Romania \\ ${ }^{2}$ "Titu Maiorescu" University Bucharest, Faculty of Medicine and Clinic Institut Fundeni \\ Center of General Surgery and Liver Transplantation, Bucharest, Romania \\ ${ }^{3}$ "Dr. Carol Davila" Central University Military Emergency Hospital, $1^{\text {st }}$ General Surgery Department, \\ Bucharest, Romania
}

\section{ABSTRACT}

By positioning the right anterior section (RAS) in the right hemiliver, the classic right hepatectomy (RH), sectionectomy or segmentectomy concept is not always appropriate for this section. Besides the classic Couinaud cranio-caudal division of RAS, there is also a vertical bipartition of RAS in two subsections (ventral and dorsal) based both on the portal systematization of the tertiary Glissonian pedicles' spatial distribution and on the suprahepatic Couinaud systematization. This study discusses the anatomical basis of the extra-Glissonian resections, as well as various types of extra-Glissonian resection involving the two RAS subsections and sparing liver parenchyma.

Key words: right anterior section (RAS), Laennec capsule and Glisson capsule, extraGlissonian access, RAS vertical bipartition.

\section{INTRODUCTION}

In the recent years' enormous progress in pre- and intra-operative explorations, as well as the emergence of state-of-the-art hepatobiliary surgery techniques led to a decrease in morbidity and mortality resulting from liver resections deemed potentially curative for both hepatocellular carcinoma (HCC) and for hepatic metastases (mainly) of colorectal origin (1-5).

If, in the case of HCC, the anatomical resections are justified by the primarily portal metastases of such tumors, the strategy is different for liver metastases where the liver is generally the "storage facility", and recurrent intra-hepatic metastases are rare. In the situations above, the anatomic resections are, compared to the non-anatomic (atypical) resections, a prognosis indicator, and the atypical liver resections spare the liver parenchyma, which may prove useful in case of a repeat surgery. There are, however, cases when the localization of a deep-seated metastasis touching or invading important vascular and biliary structures renders a non-anatomic resection insufficient or even dangerous from an oncology point of view. 
Such cases require an anatomic resection which, however, in case of a right posterosuperior localization in the liver, may lead to sacrificing an excessive portion of parenchyma, when compared to the size of the tumor. On the other hand, the association of an $\mathrm{HCC}$ with liver pathology (cirrhosis), frequent in Asian countries, might require a conservative anatomic resection lifting the tumor-affected portal liver area, thus avoiding a potential postoperative liver failure (4).

Using state-of-the-art CT scanners, as well as such scanners in association with special software (HepaVision) allows for 3D rendering of vascular and biliary elements down to subsegmental levels (1,6-12).

At present, they allow for a real-time mapping of each liver area, both for portal and arterial irrigation, and biliary and venous drainage (13). Moreover, such areas, after being volume-quantified, the maps may be overlaid (fusion image) to determine to what extent the blood flow map coincides with the venous drainage map in the same liver area (14).

Virtual hepatectomies with 3D quantitative (volume), qualitative (congestion areas) and afferent and efferent blood flow investigations both for the remaining and the resected parenchyma are now possible (15).

Several types of surgery based on the vertical bipartition of the right anterior section of the liver (RAS) were performed in recent years, while attempting to perform a series of anatomic resections, liver parenchyma-sparing and useful in cases of HCC and liver metastasis surgery $(8,10-12,14,16-23)$.

We will use the terminology established for liver anatomy and surgical techniques in The Brisbane 2000 Terminology of Liver Anatomy and Resections, approved by the International Committee of the International Hepato-Pancreato-Biliary Association (2426). According to Belghiti, the foundation of the Brisbane liver segmentation is the Couinaud segment $(\mathrm{Sg})$, defined of the latter as the liver area dependent on the tertiary Glissonian pedicles (GP) (25). At a subsegmental level, each tertiary GP irrigates and drains a cone-shaped liver area with a peripheral base, named "cone unit" by Takasaki (27). A Couinaud Sg includes up to 3-4 cone units, representing, in practice, the smallest liver areas that can be subject to an anatomic resection (27-29).

Couinaud described in 1957 three different accesses to portal pedicles, i.e.: the classic hilar (intrafascial) access by individual dissection of the vascular and biliary elements, the extrafascial (extra-Glissonian) access and the transfissural extra-
Glissonian access (18,30-37).

If the classic hilar access is used frequently for the right or left hepatectomies $(\mathrm{RH}, \mathrm{LH})$, the issue is entirely different for the sectional or segmental resections, where individual vascular and biliary dissection is difficult, dangerous or even impossible $(30-32,38)$.

In such interventions, the extra-Glissonian portal pedicle isolation allowed, according to Couinaud, for 'solving the technical issues of some well-defined liver resections that seemed impossible to perform by direct hilum dissection' (31).

Couinaud's description of the portal pedicles' extraGlissonian isolation was the beginning of the extraGlissonian resection era and we can state, without being blasphemous, that "nihil sine ... Couinaud" is entirely true in this field.

\section{The anatomic and surgical basis \\ for extra-Glissonian resections: the Laennec and Glisson capsules}

Besides the peritoneum, the liver is wrapped in a thin, fibrous membrane described by Laennec, usually wrapping the entire surface of the liver, except for its bare area (41).

A second fibrous component with dense connective tissue is located in the proximity of the liver hilum, interposed between the vascular and biliary elements and the liver; this is the only anatomic structure to be identified as the Glisson capsule (the perivascular fibrous capsule). This capsule was noticed by Walaeus in 1640 and later described by Glisson in 1642 $(18,30,31,39,40,41)$. According to Couinaud (31), the Glisson capsule ensemble includes two anatomic structures, i.e.:

- a structure in the inferior hepatic side plane, the so-called portal plate, with four contiguous components, i.e. the hemicylindrical hilar plate (HP), the umbilical plate (UP), the cystic plate and the Arantian plate (figure 1).

- a second, more complex, anatomic component, comprising all the connective tissue sheaths derived from the HP and the UP that envelop various portal pedicles and turn, at the liver point of entry, into Glissonian (Walaean) pedicles in the shape of fibrous bands consisting each of a single anatomical and functional structure with major surgical implications (28-31,33-35,38,42).

Later, Launois and Jamieson, followed by a series of other authors, made important contribution to the anatomy - and surgery - related studies on the Glisson capsule $(33-35,39-41,43,44)$. 


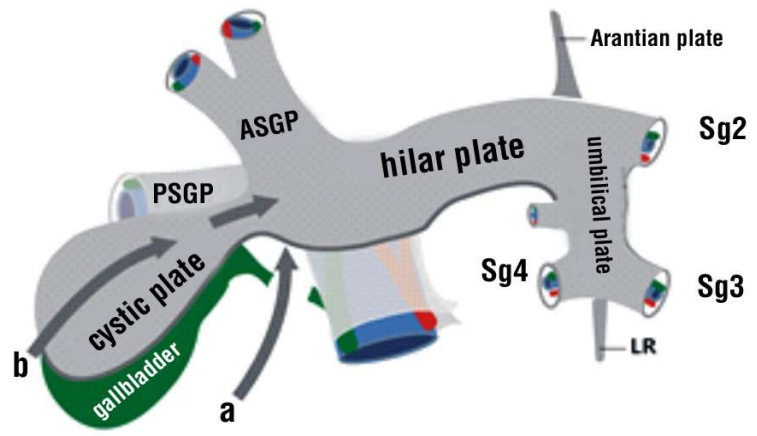

Figure 1 - The Glisson (Walaeus) capsule with the 4 portal plates. a. Classic hilar ASGP access by sectioning the cystic plate and take down the HP. b. ASGP access using a "monoblock" dissection of the cholecyst and the cystic plate (Sugioka), ASGP, PSGP (the anterior and, respectively, posterior sectional Glissonian pedicles)

In Couinaud's 1989 (30) monography, the elegant study of De Brux's microscopic sections indicated a contiguity, near the liver hilum, of the Laennec capsule, between the four portal plates and the liver, thus demonstrating the existence of a micron-measurable anatomic space between the Laennec capsule and the Glisson capsule (45). This space was confirmed and expanded upon by other authors such as Sugioka et al., highlighting the intrahepatic continuity of the Laennec capsule, separating the GP as well as the hepatic veins from the parenchyma, in contrast with the classic approach stating that the aforementioned anatomic structures were in direct contact with the liver tissue $(41,45)$. These authors also highlighted the surgical relevance of this anatomic position, allowing for isolating the GP and hepatic veins at both the hilar and intra-hepatic levels, thus avoiding tissue destruction $(41,45)$.

$\mathrm{HP}$, a central element of the Glisson capsule, wraps, over a hemicylindrical cross-section, the portal triad of elements that are comprised in the two main Glissonian pedicles (GP), i.e. right (RMGP) and left (LMGP) (figure 1).

In case of a modal distribution $(70 \%-90 \%$ of the cases), for RMGP we notice two major sectional GPs, i.e.:

- Anterior sectional GP (ASGP) entering the liver vertically for the right anterior section (RAS), with Sg 5 and Sg 8. (figure 1)

- Posterior sectional GP (PSGP) towards the right posterior section (RPS), maintaining initially the horizontal plane and then distributed in $\mathrm{Sg} 6$ and Sg 7. (figure 1)

\section{The right anterior section}

This section, without any anatomic landmark on the superior hepatic side is the largest of the four hepatic sections, comprising $36.2 \%$ of the total hepatic volume (THV) $(1,13,14)$, and bordering on the two main intersectional planes, i.e. the right intersectional plane (RIP) with the right hepatic vein (RHV) and on the left, middle hepatic plane (MHP, Couinaud main portal fissure) with the middle hepatic vein (MHV).

In these intersectional planes, RAS is separated from RPS and the left medial section (Sg 4) and, on the posterior side, from the caudate lobe $(\mathrm{CL})$ by a virtual plane with an ascending angle, the so-called dorsal portal fissure (DoPF or pre-caudate plane), starting at the RMGP and ending under the hepato-caval confluence of MHV and RHV. In RAS it main antero-superior component is Sg 8, including almost $2 \beta$ of this section (16).

- Sg 8 is the largest liver segment and, in the postero-superior position, the tertiary GPs of this area may frequently transgress, with RIP in Sg 7; in such cases, RHV, usually located in this plane, is no longer an anatomic landmark for the two sections (46).

- Sg 5, in the antero-inferior portion of RAS, has a variable size, due to the RIP versatility in relation to the anterior border of the right hemiliver (30-35).

In its ascending trajectory of an average of $1.5-2$ $\mathrm{cm}$ with thickness between $1-3.1 \mathrm{~cm}(47,48)$, ASGP having a curve with a posterior concavity and its division in tertiary GPs establishes the segmentation pattern of RAS (16). Depending on the ASGP and tertiary GP ramification pattern, there are multiple anatomic variations, i.e.:

- the classic, cranio-caudal bipartition (Couinaud), present in $7 \%-53 \%$ of the cases $(1,15,20)$ (figure 2a);

- the vertical ventro-dorsal (Y-shaped) bipartition, present in $17 \%-100 \%$ of the cases $(6,8,15,20,49)$ (figure $2 b$ ) In this case, the ASGP stem is divided in two short branches (GP 8v, GP 8d) (figure 2c), as the starting point towards the ventral and dorsal areas of 6-8 radially positioned tertiary GPs for the superior three quarters, i.e. for Sg 8 (16).

- the tripartition (a ventro-dorso-caudal division present in $13 \%-32 \%$ of the cases $(1,20)$ (figure 2d-e)

- the stem-like appearance of ASGP (type "I" Takasaki type $\mathrm{C}$ ) as the base of radially positioned tertiary GPs.

- the duplicate ASGP type (U-type) is quite rare $(>10 \%$ of the cases),

While Couinaud is sometimes credited with a simplistic approach of the ASGP cranio-caudal division 
Figure 2 - RAS bipartition types

a. Couinaud cranio-caudal division;

b. Ventro-dorsal bipartition; c. Intra-operative ultrasound ASGP appearance (Y-type);

d, e. tripartition and dissection specimen

RVP (right vena porta)

ASV (anterior right sectional vein)

ASGP (anterior right sectional Glissonian pedicle)
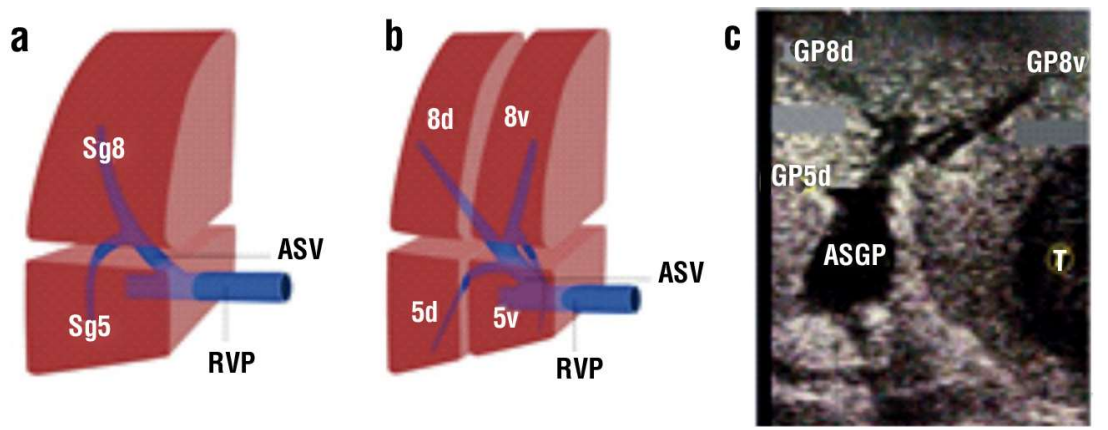

d

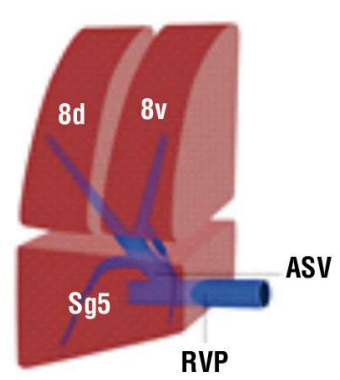

e

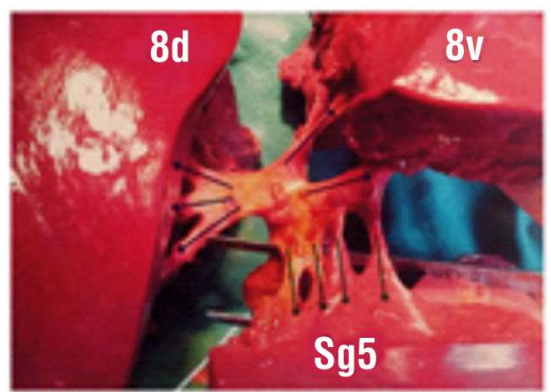

(Sg $8+$ Sg 5), in reality, he described all the division variations for the anterior sectional vein (ASV), such as the modal division (Y-type), the early division, the stem type (I-type), the duplicate type (U-type) in 1957 and, later, in 1989 (30,31).

Hjortsjo was describing, in 1951, a right hemiliver tripartition-type portal segmentation, identifying three segments in this area, i.e.: ventro-caudal, intermediate, and dorsocaudal; in this segmentation,ț ventro-caudal and intermediate corresponding to RAS, and dorsocaudal corresponding to RPS (50).

In this segmentation the ventro-caudal and intermediate segments are separated vertically by a ventral right segmental fissure including a hepatic vein (identified by Couinaud in 1957 as the Sg 8 vein). The Kogure et al. anatomic study (16) confirms Hjortsjo's approach and proposes a new update for it, defining the ventral right segmental fissure that anterior segmental fissure (AF) and the vein of this portal fissure includes as the intersubsegmental vein, draining mainly (54.4\%) into the MHV. The Hjortsjo-Kogure segmentation pattern was validated later, mainly by using modern imaging tools, following the papers of Cho et al., as well as of other authors, and highlighting the surgical implications of this type of segmentation (6-8,10-12, $14,15,20,49,51)$.

We can therefore speak of a vertical RAS bipartition in a ventral subsection $(S)(S 8 v+5 v)$ with a ventro-cranial (8v) and a ventro-caudal (5v) subsegments, as well as of a dorsal subsection ( $(8 \mathrm{~d}+5 \mathrm{~d}$ ) with a cranio-dorsal (8d) and a caudo-dorsal ( $5 \mathrm{~d}$ ) subsegments (figure $2 b$ ). These two subsections, present in $100 \%$ of the cases according to Cho et al. $(6,7,49)$ are close in volumes, separated only by right anterior fissure plane (AF, Hjortsjo-Kogure) or the plane we call the right anterior intersubsectional plane (AISP).

This plane includes the anterior fissure vein (AFV), also named the intermediate vein (V8i) (49), that we chose to name the anterior intersubsectional vein (AISV). The AISV (V8i) is present in $85 \%-100 \%$ of the cases, and it usually is a vein afferent to MHV (54.4\%$83.9 \%$ of the cases) and, less frequently, a vein afferent to RHV or the inferior vena cava (IVC) $(6,7,10,15,16,49)$.

An important anatomic detail is that as AISP level, considered portal of Hjortsjo and Kogure is found distal, at the hilar level, ASGP $(13,16)$. Besides AISV (V8i), the main vein in Sg 8, starting between the two posterosuperior ASGP GPs of the two subsections, there are other tributary veins draining these two subsections, as follows:

- for the ventral subsection, the $8 \mathrm{v}(\mathrm{V} 8 \mathrm{v})$ ventral veins, present in half of the cases, afferent to MHV either below the AISV level (67\% of the cases) or, less frequently, above it (13).

- for the dorsal subsection, a dorsal vein afferent to RHV (V8d) is present in $100 \%$ of the cases. 
Sg 5 drainage has individual variations, but $\mathrm{V} 5 \mathrm{v}$ and V5d are constantly present $(13,51)$.

\section{RAS bipartition according to the suprahepatic segmentation}

Besides this vertical portal division of RAS, there is another vertical division, based on the Couinaud suprahepatic segmentation, with 3 sectors: the right sector, drained by RHV, the median sector, drained by $\mathrm{MHV}$ and the left sector, with the left hepatic vein (LHV) (30-32). As this suprahepatic systematization alternates with the portal systematization it is possible, in some situations, that the venous segmentation-based resections are not only anatomic, but also more liver parenchyma-sparing. When speaking about RAS, the delimitation of the right suprahepatic sector (RHV) from the median suprahepatic sector (MHV) is the right suprahepatic fissure (RSHF) and, as it is we know, ASGP is in a distal position by this fissure. According to Couinaud, due to the RSHF anterior variability, it divides RAS vertically in two approximately equal areas in only $60 \%$ of the cases (32) (figure 3).

Described in a visionary manner by Couinaud as early as 1957, the suprahepatic resections were difficult to perform due to the RSHF intra-operative objectivation being impossible by simply clamping RHV or MHV. After clamping a major vein, the mechanism to avoid the congestion of an area dependent on such veins consists, mainly, of reverting the area's capillary and sinusoid blood flow towards the portal system. Practically, vena porta becomes an efferent vein for the clamped area, based solely on the arterial blood flow $(52,53)$. Therefore, arterial clamping must be associated to venous clamping to expose RSHF, thus removing this irrigation source and lowering sinusoid pressure. This double clamping test was described by Sano and Makuuchi (52), allowing for performing the venous resections described by Couinaud.

\section{Surgical techniques based on the extra- Glissonian vertical RAS bipartition}

The extra-Glissonian ASGP approach is much easier to perform, in a vertical RAS division anatomic hepatectomy, than using the classic hilar dissection of the vascular and biliary elements of this sectional pedicle $(2,27-30,33-36,38-40,42)$.

\section{RMGP extra-Glissonian isolation}

Almost all RMGP isolation techniques are based on

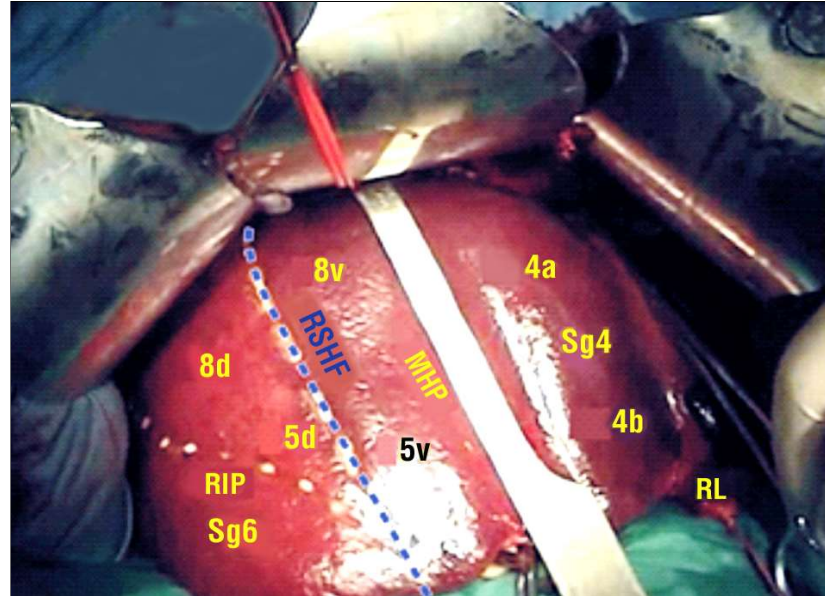

Figure 3 - RAS vertical bipartition after Couinaud suprahepatic systematization

RSHF (right suprahepatic fissure), RIP (right intersectional plane), MHP (middle hepatic plane), RL - rounded ligament

the HP detachment (lowering) maneuver, associated (post cholecystectomy) to sectioning the cystic plate over its insertion line on the anterior edge of HP.

These 2 maneuvers were initially described in 1956 by Hepp and Couinaud for wider access to the biliary confluence and the left hepatic duct (LHD) and, later, Couinaud included the 2 maneuvers in the hepatic extra-Glissonian resection techniques $(30,31,54)$. The insertion point between the cystic plate and HP is important for at least 2 reasons, i.e.: it is a fixed landmark for the MHP (main portal fissure) position at hilum level on the inferior hepatic side and it also acts as a warning for the surgeon, in case the insertion of this plate on HP is next to RMGP, of a vascular and biliary modal positioning in the right hemiliver in more than $80 \%$ of the cases (30). Sectioning the cystic plate (figure 1a) allows for a wider ulterior RMGP mobilization and better access to ASGP $(30,31,55)$. HP lowering (the Couinaud-Hepp maneuver) is performed using a larger or smaller electrosurgical incision in the peritoneal serous membrane, by the posterior edge of subsegment $4 \mathrm{~b}$ (the quadrate lobe) and right above RMGP (1-2 $\mathrm{mm}$ away from it) from the reflection of the peritoneal serous membrane on this pedicle (56). For a full isolation of RMGP, the HP detachment must be accompanied by a retro-hilar incision which, actually, singularizes to a reasonable extent the various existing techniques. At a retro-hilar level, in the caudate process area ( $\mathrm{CPr})$, the place, as well as the positioning of the second incision, larger, that may involve a higher degree of tissue destruction (along with potential bleeding) or smaller, makes, actually, the difference between an extra-Glissonian, intrahepatic, isolation of RMGP and, preferably an extra-hepatic isolation (41). A $1-2 \mathrm{~cm}$ 


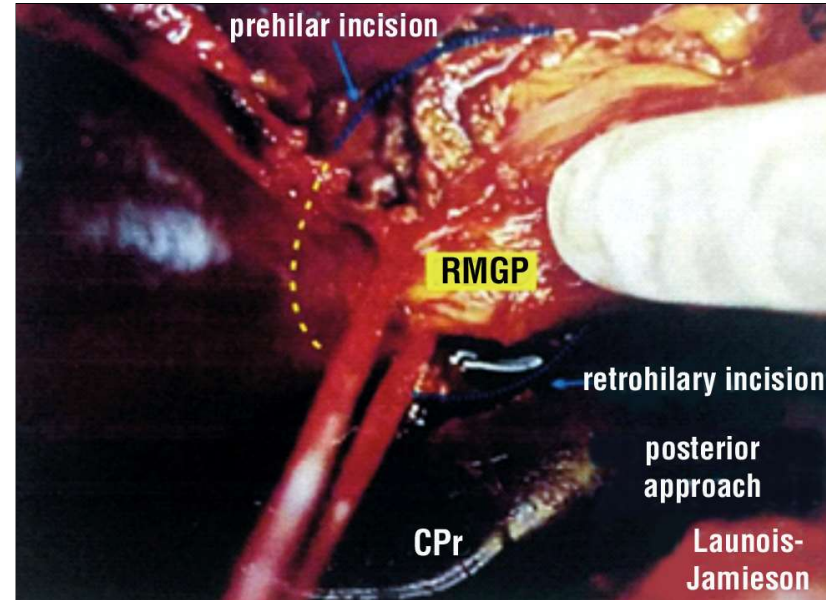

Figure 4 - Launois-Jamieson-type extra-Glissonian and intra-hepatic isolation (posterior approach), RMGP (right main Glissonian pedicle), $C P r$ (caudate process)

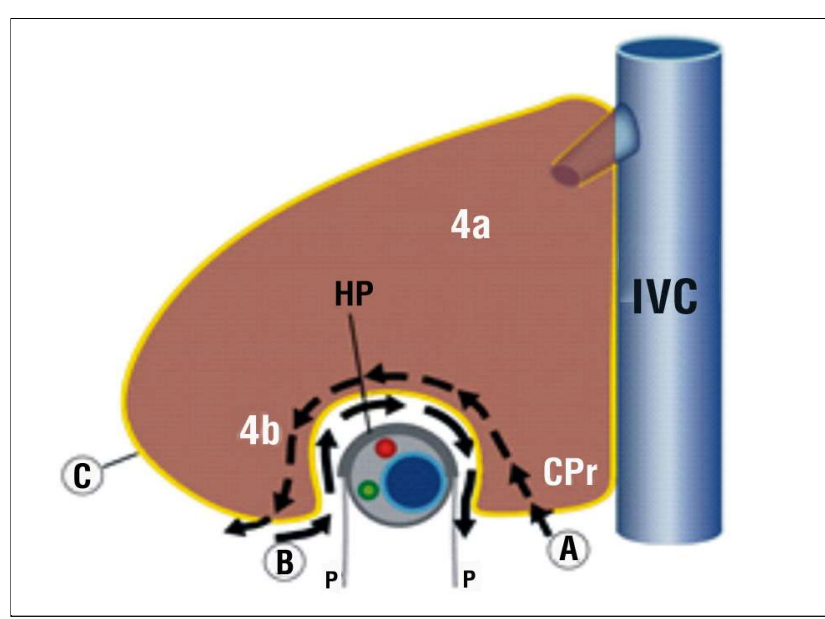

Figure 5 - The two portal pedicle isolation methods at a hilum level: A. Intra-hepatic; B. Extra-hepatic; HP (hilar plate), C (Laennec capsule), $\mathrm{P}$ (peritoneum), IVC (inferior vena cava) $\mathrm{CPr}$ - caudate process

incision in the $\mathrm{CPr}$, Launois-Jamieson-type, technique (posterior approach) (figure 4) or a mini-incision $\mathrm{CPr}$ and Sg 7, Machado et. al-type, making these two techniques both extra-Glissonian and intra-hepatic. The Machado et al. technique avoids, however, the central area of $\mathrm{CPr}$ (where bleeding may occur due to intercepting the $\mathrm{CPr}$ vein) and, thus, does not require an associated the Pringle maneuver (57). The extraGlissonian and extra-hepatic RMGP detachment implies, in theory, a HP detachment maneuver performed in the plane between the Glisson and the Laennec capsules (figure 5). In practice, for this maneuver, the surgeon must direct the vascular clamp inserted after initiating the HP detachment following a posterior semicircular pattern in contact with the HP rigid plane, with a posterior exit point precisely between lower edge of RMGP and the CPr upper edge (figure 6),

Any resistance the clamp might encounter over the posterior side of RMGP may result from the present GP of caudate lobe $(C L)$, requiring to partially remove the clamp and change its trajectory. In fact, the technique Couinaud suggested in 1957 and described extensively in 1985 for the LMGP isolation, as well as the Takasaki and Batignani-Strasberg RMGP isolation techniques $(28,29,31,36,42,55,58)$ are extra-Glissonian and extrahepatic although these authors do not explicitly state that after the HP detachment the liver parenchyma border of the detached spaced is the Laennec capsule, possibly with a better visibility when using laparoscopic or robotic surgery $(41,45)$. In approximately $10 \%-30 \%$ of the cases, RMGP is replaced by the two sectional GPs (figure 7), an anatomic circumstance modifying the

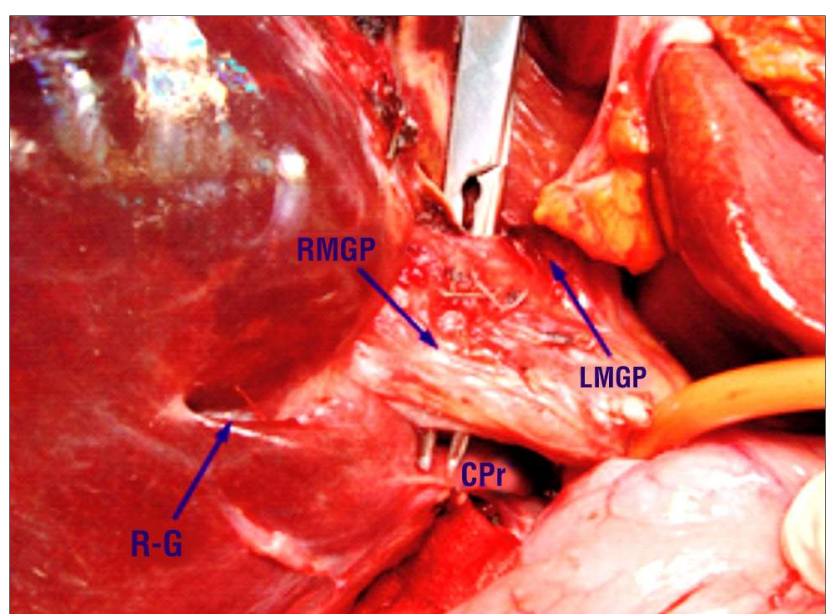

Figure 6 - Extraglissonian and extrahepatic isolation of right main glissonian pedicle (RMGP), LMGP - Left main Glissonian pedicle, R-G (Rouviere-Gans incisura)

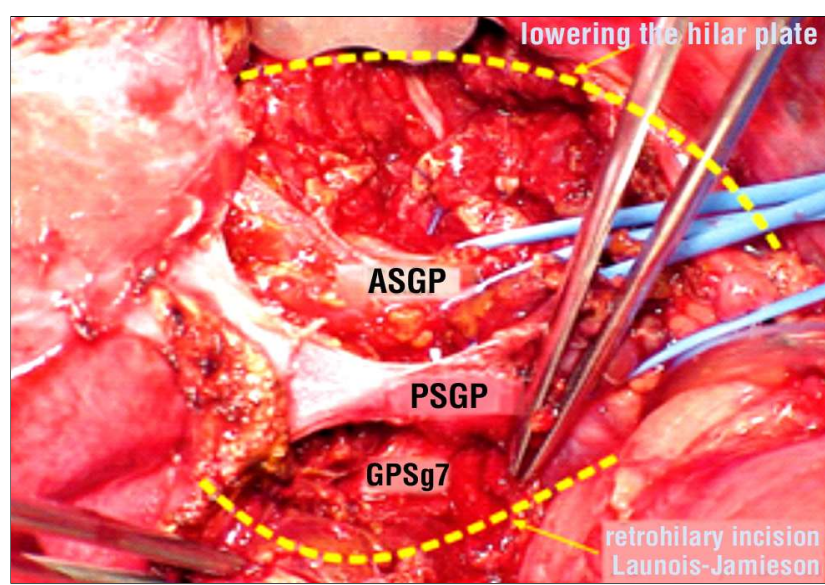

Figure 7 - RMGP absent; ASGP - anterior sectional Glissonian pedicle), PSGP - posterior sectional Glissonian pedicle, forming at the right edge of vena porta (VP), GP Sg7 - Sg7 Glissonian pedicle. 
Glisson capsule morphology and leading to an incomplete vascular control of the right hemiliver and to a more difficult ASGP isolation, later $(3,56,59)$.

\section{ASGP and tertiary GPs isolation}

Once RMGP was isolated with umbilical type, it can be tractioned (Okamoto maneuver) and dislocated from the hilum, thus facilitating, along with the cystic plate sectioning, the access to ASGP. Besides this RMGP preparatory isolation method for access to ASGP there are at least 3 more access methods to this sectional GP, i.e.:

- a transection of the liver parenchyma on the MHP trajectory (Couinaud main anterior fissure access), to the immediate right of MHV, opening the liver like a book, at a pre-hilar level, up to the HP level. This access, involving notable tissue destruction, allows for exposing both the two main GPs (right and left) and the right sectional GPs (figure 8). ASGP is located at approximately $1.5-2 \mathrm{~cm}$ to the right of the hepatic transection plane, in contact with the HP, and its tertiary GPs can be easily isolated.

- an anterior transection at the level of RIP; however, due to the previous variability of this plan, the method is rarely used.

- finally, Sugioka et al. (41) have recently proposed a "monoblock" dissection, cholecyst and cystic plate, dissection in the plane separating the later from the Laennec capsule (cystic plate cholecystectomy) for ASGP isolation (figure 1b). The ASGP and tertiary GPs' isolation is the key-moment in the RAS vertical bipartition because clamping it causes, at first, a ischemic objectivation of this section's borders, as given by the two major intersectional planes (RIP and MHP). ASGP, vertically penetrating RAS, and have an intrahepatic origin in $75.7 \%$ of the cases $(47,48)$; in approximately $24.3 \%$, ASGP is of extra-hepatic origin and, in such cases, this reveals an anatomic variation of VP (trifurcations are more frequent) (47).

As a rule, ASGP is located within the parenchyma, behind the cystic plate $(38,60,61)$ and a recent study by Ammar et al. reveals that this position is only present in $56.8 \%$ of the cases, and that in $35.1 \%$ of the cases ASGP is located, on average, $1.4 \mathrm{~cm}$ to the right of the cystic plate, between it and the upper edge of the RouviereGans incisura, when present (roughly over $2 \beta$ of the cases). (18). The parenchyma is dissected behind the sectioned cystic plate by traction on RMGP and ASGP is isolated at $1-2 \mathrm{~cm}$ in the parenchima. According to

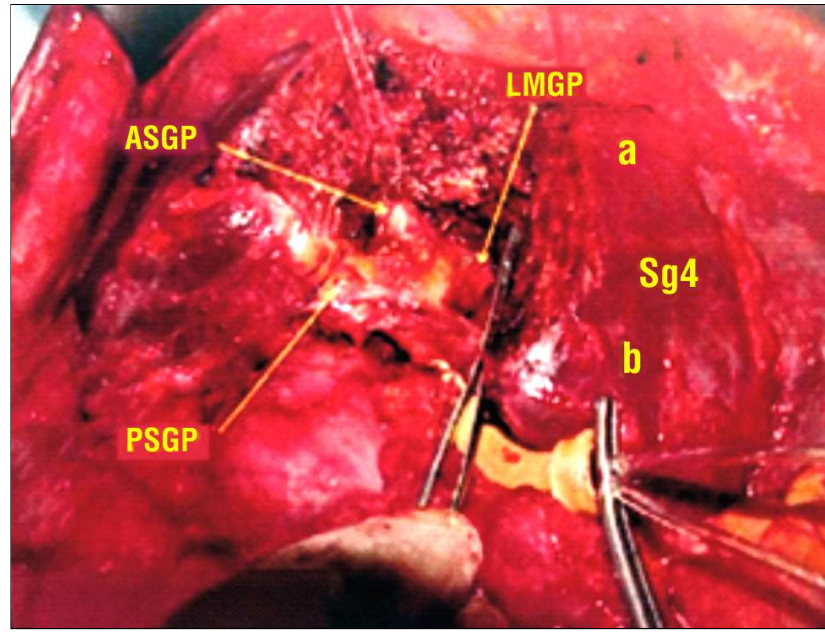

Figure 8 - MHP - Middle hepatic plane parenchyma transection (the Couinaud main anterior fissure access). Wide access to RMGP and LMGP and the sectional GPs (ASGP, PSGP)

Regimbeau et al., the resistance while isolating the posterior side of this GP may be due to an atypical GP anatomic location at hilar level(56). Using the Machado et al. technique, the intra-hepatic isolation is performed using 2 micro-incisions, one in a pre-hilar (right above HP) position, and the other on the right edge of the posterior cystic plate portion, with the clamp inserted (blind) deeply in the parenchyma, behind the aforementioned plate (57). If the ASGP isolation, lasting 5-7 minutes, is performed in contact with ASGP, the isolation might also be extra-hepatic, between the Glissonian sheath and the intra-hepatic Laennec capsule $(41,45)$. The ASGP clamping objectivation ischemic on the diaphragmatic liver side - RAS, with the two intersectional planes to be traced with the electrosurgical scalpel. The practical isolation of the tertiary GP for Sg 5 and Sg 8 for the two subsections (ventral and dorsal) is a relatively difficult situation as the two pedicles are located far inside the liver in relation to the inferior hepatic side $(27,39)$. According to Galperin and Karagiulian the Sg 5 GPs are located inside the liver at a variable distance of $1.8-3 \mathrm{~cm}$, and the Sg 8 GPS at $2.9-4 \mathrm{~cm}$ form the hepatic hilum (62). Sg 5 GPs (varying from 1 to $7 \mathrm{GPs}$ ) stem, mainly, from the ASGP stem in almost half of the cases $(47.29 \%)$ or from the initial curvature of the 2 postero-superior GPs $(40.90 \%)$, and more frequently from GP8v. $(30,63)$. Using CT+3D imaging, Tanaka et al. identify 1-5 tertiary GPs for $5 \mathrm{v}$ and 1-4 tertiary GPs for $5 d$ (14). There are, usually, 1-3 tertiary GPs for 8v (1.53 on average) and 1-3 tertiary GPs for $8 d$ ( 2 on average) $(14,64)$. The difficulties encountered in identifying such tertiary GPs depend on the ASGP anatomic type (Y-type in half of the cases) and especially on the distance from the division point 


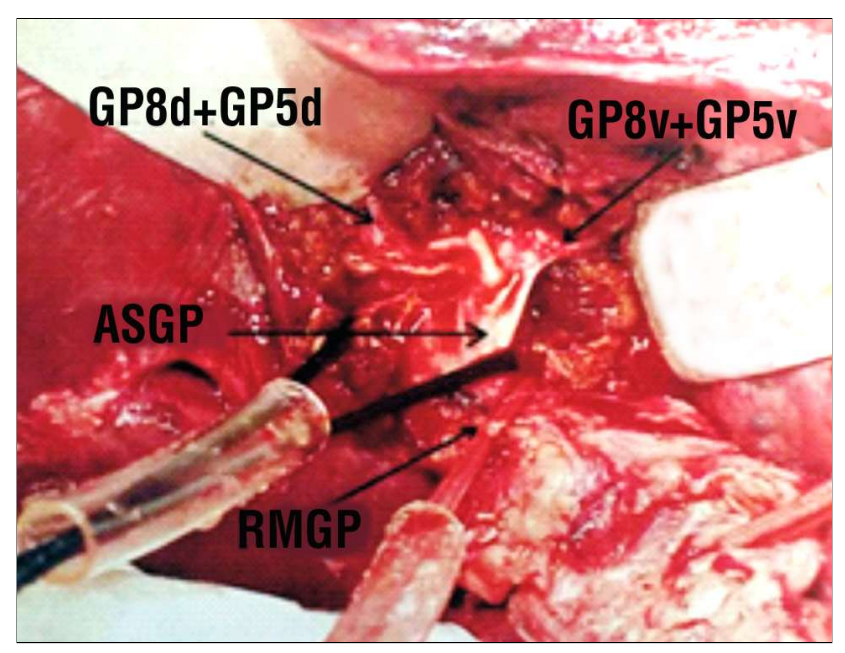

Figure 9 - Access to ASGP and the tertiary GPs after a cystic plate vertical hepatotomy, RMGP - right main Glissonian pedicle

between this major GP and the hilar plane, in the two postero-superior GPs for $\mathrm{Sg} \mathrm{8.} \mathrm{It} \mathrm{is} \mathrm{also} \mathrm{worth}$ mentioning that the tertiary GP isolation for $\mathrm{Sg} 5$ and 8 was already described in detail in 1987 by Okamoto et al., who were the first to use, in Asian literature, the anatomic notions of HP and cystic plate $(60,65)$. These authors have initially associated the HP detachment with a partial mobilization of subsegment $4 \mathrm{~b}$ (the quadrate lobe) by sectioning 2-3 GPs immediately to the right of the falciform ligament for wide access to the 2 major GPs and ASGP and its tertiary GPs (the unroofing method), The ASGP anterior side was dissected by traction, and then the relevant section tertiary GPs were isolated and clamped.

If this initial access to the tertiary GPs is limited, a vertical hepatotomy of $1-2 \mathrm{~cm}$ may be performed, focused on ASGP at the cystic plate level (figure 9) $(27,33,58)$. Opening AISP from the anterior hepatic edge to the isolated ASGP is, according to Cho et al. (49), the third access to this sectional pedicle (the other two are the main and the umbilical fissure accesses) (figure 10, 11). In the less frequent case when the anatomical shape of ASGP is a long stem (I-type, C-type, Takasaki) (figure 12), the tertiary GP interception is incomplete, and a pre-hilum opening of AISP will be necessary, by initially approaching the Sg5 GPs. Besides this portal exposure of AISP, there is also the alternative solution of exposing this intersubsectional plane by using the Sano-Makuuchi test venous occlusion method.

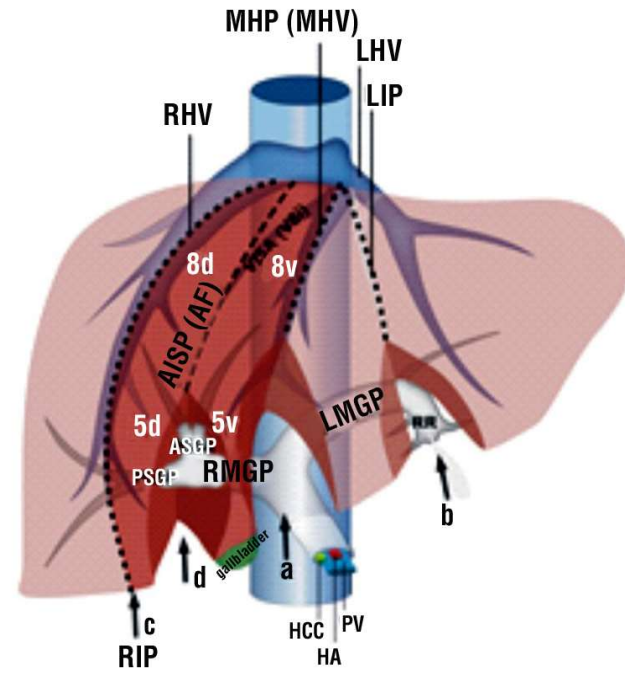

Figure 10 - The third ASGP access via AISP (anterior intersubsectional plane), AF (anterior fissure), a (main fissure access), b (umbilical access), c (RIP access - anterior intersubsectional plane), HCC (hepatocholedoc channel), PV (portal vein), HA (hepatic artery), RHV, MHV, LHV - right, middle and left hepatic veins, MHP - middle hepatic plane, LIP - left intersectional plane (umbilical fissure)

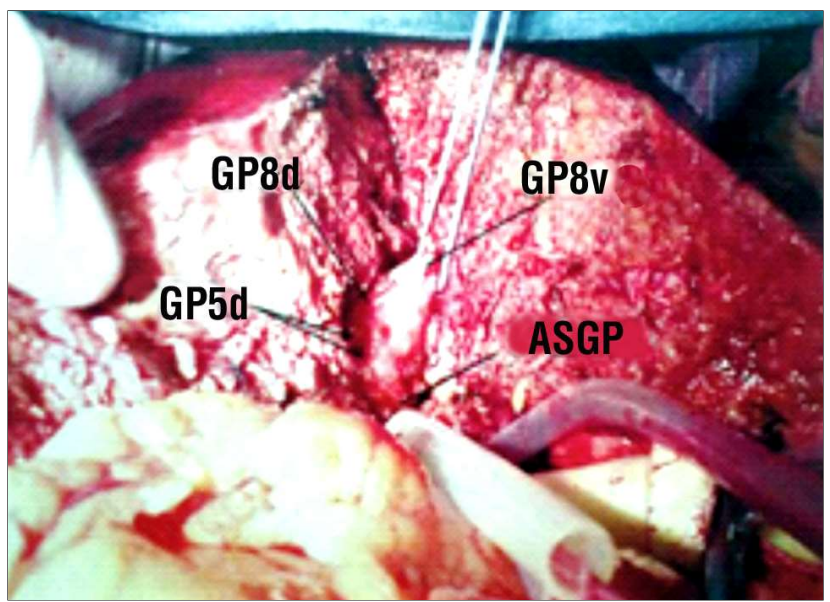

Figure 11 - Vertical transection of the liver parenchyma in the right anterior intersubsectional plane (AISP), isolating GP8v and GP5v

\section{Liver parenchyma-sparing anatomic resections based on the RAS vertical bipartition}

Multiple types of resection involving the two RAS subsections may be performed, depending on the liver function, the size and localization of the tumor formation, i.e.:

Right ventral subsectionectomy $(S 8 v+5 v)$

This type of surgery (figure $13 A-B$ ) starts with an 


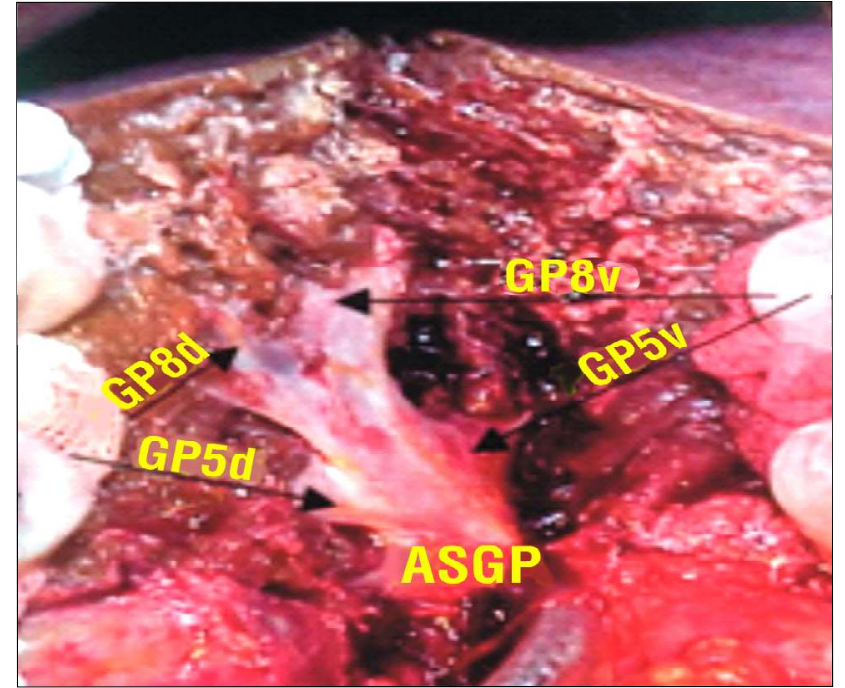

Figure 12 - Anatomy of ASGP: Couinaud type-I or Takasaki C-type stem

extra-Glissonian isolation (extra- or intra-hepatic) of RMGP, followed by its clamping and MHP objectivation (main portal fissure). Initially, the hepatic transection is pre-hilar, immediately to the right of MHV, up to the level of the superior side of HP and intercepting V5v, as the right initial point of MHV which, when larger in size, implies a wider area drained by MHV and in Sg 6 (13\%-15\% of cases) $(30,31)$. The ASGP stem is isolated above $\mathrm{HP}$, in contact with it and immediately to the right of the transection plane $(1.5-2 \mathrm{~cm})$, followed by clamping the ventral branch for $58 v+5 v$ or, if GP5v stem separately from the ASGP stem, followed by ligating them separately. AISP is thus exposed, opening it from the anterior hepatic edge both towards the ASGP isolated at the hilar level and in the cranial direction, towards the right edge of the MHV terminal portion, isolating, in the dissection plane, AISV (V8i,V8) that may, depending on its trajectory, stay on the dorsal subsection $(S 8 d+5 d)$. If $\mathrm{CL}$ is maintained, $8 \mathrm{v}$ is resected from it, in the plane of DoPF; if not, the resection will expose the anterior side of the retro-hepatic IVC.

Right ventral subsectionectomy ( $S 8 v+5 v)$, associated to the resection of the left medial section ( $\mathrm{Sg} 4)$

This resection (figure $13 \mathrm{~A}-\mathrm{C}$ ) is, in fact, an alternative to a central bi-sectionectomy (Sg 4+5+8) and includes removing the MHV draining sector, i.e. the Couinaud median suprahepatic sector; Couinaud has described this surgery as the suprahepatic median or intermediate suprahepatic sectorectomy (31). Later, there was a brief description of this surgery by

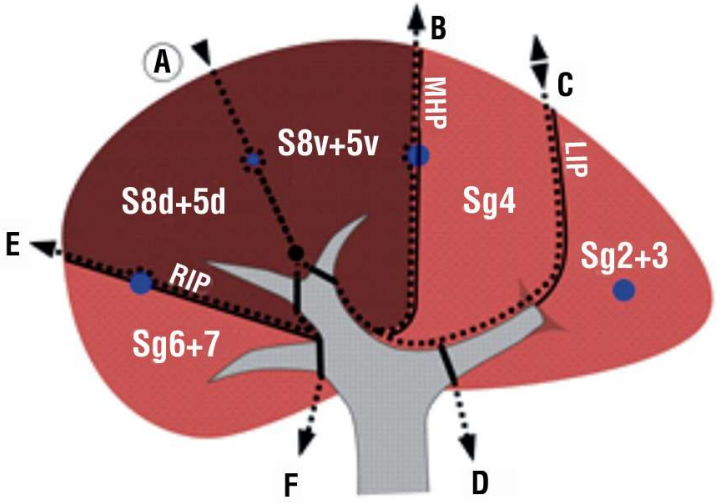

Figure 13 - Liver sparing anatomic resection types, based on the RAS vertical bipartition (explained in the text)

Kanemura et al., followed by a detailed description by Kondo et al (19). The technique described by the later involves a surgery starting with a parenchyma transection in Sg 4, immediately to the right of the falciform ligament and intercepting in this area's GPs within the parenchyma; in the superior area, the common stem of MHV and LHV is isolated and then, using the Sano-Makuuchi test (MHV + proper hepatic artery clamping) is delimited AISP, located in the middle of RAS, previously objectivized by clamping ASGP isolated from the hilum. The parenchyma transection is bi-directional: on the inferior side, towards ASGP with a ligature of S8v-5V GP, and then, on the superior side, towards the MHV stem to be ligatured at the end. $\mathrm{CL}$ conservation will lead to a posterior resection plane at the DoPF level and under the ligatured MHV.

\section{Right ventral subsectionectomy $(S 8 v+5 v)$ associated to a left hepatectomy (LH)}

This major resection (figure $13 A-D$ ) may, in certain cases, successfully replace a classic left tri-sectionectomy, providing, compared to the later, two major advantages, i.e.:

- first is avoid a parenchyma transection by the extremely large coronal in situ RIP (almost equal in width with the right hemiliver) that is also variable in relation to the anterior edge of the right liver (30,32-35,38).

- also, this surgery may provide a better conservation of the liver parenchyma, compared to the classic major resection, and this is important in case of liver pathology.

There are two options for performing this surgery that, in practice, concern the AISP exposure manner, i.e.: 


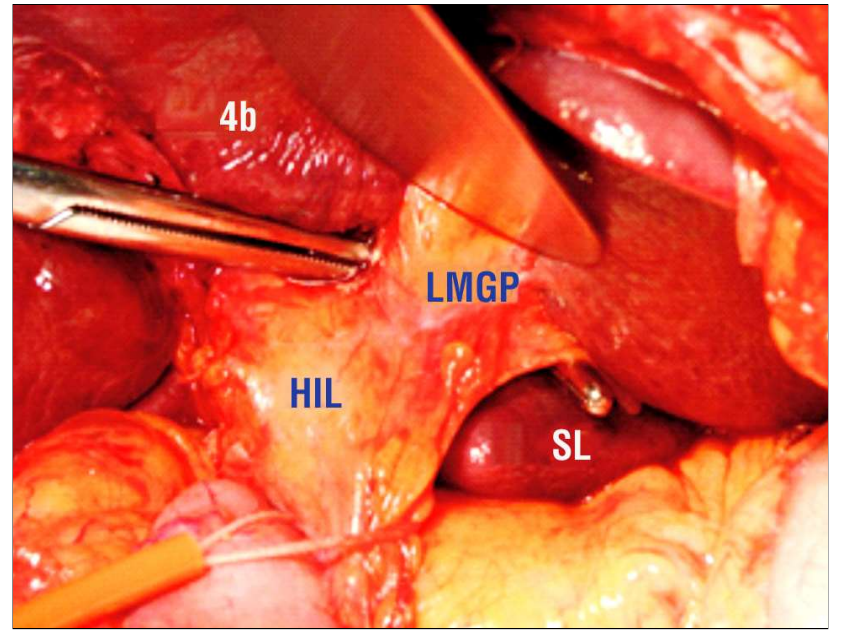

Figure 14 - Extra-Glissonian and extra-hepatic isolation of the left main Glissonian pedicle (LMGP), SL- Spigel lobe

- with the first option, AISP is exposed over the suprahepatic systematization; this procedure was described by Couinaud as the sinistro-median suprahepatic resection and we have performed it in $2005(17,18,31)$. Basically, the resection starts with a large detachment of the HP, sectioning the cystic plate and isolating RMGP and ASGP, clamped to delimitate RAS. LMGP is subject to an extra-Glissonian isolation by the left hilum extremity, and sectioned (figure 14). Then, the left hemiliver is mobilized and, after the left component of the IVC ligament (Makuuchi) and the Arantius ligament are ligatured, the common stem of MHV and LHV are isolated, followed by ligaturing and sectioning the later. The SanoMakuuchi test (clamping the MHV and the proper hepatic artery), by exposing AISP, using a hepatic dissection directed towards ASGP, along with intercepting $S 8 v+5 v$ GPs, followed by a parenchyma transection reaching MHV in the superior portion, followed by the sectioning of the later (figure 15).

- with the second option, the GP-related hilar step, as well as the left hemiliver mobilization are identical to the first description, with or without a dissection and isolation of the common MHV + LHV stem. AISP is exposed by the ischemic delimitation resulting from the $S 8 v+5 v$ GP ligature, and the parenchyma transection will intercept at the end, if not previously, the common MHV+LHV stem or their individual sectioning.

\section{Right dorsal subsectionectomy $(S 8 d+5 d)$}

The indications for this surgery (figure $13 A-E$ ) are

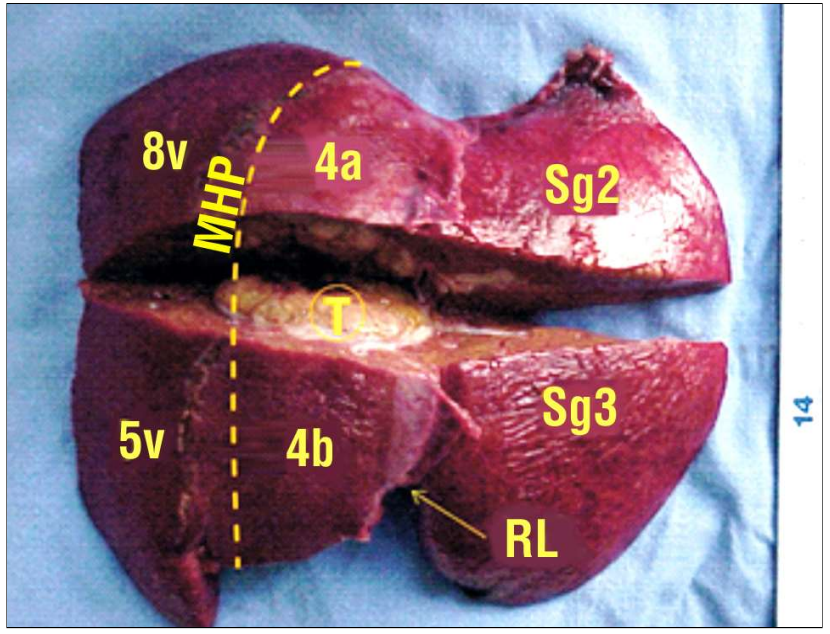

Figure 15 - Right ventral subsectionectomy $(S 8 v+S 5 v)+$ left hepatectomy (LH) (Couinaud sinistro-median suprahepatic resection, MHP (middle hepatic plane), RL. (round ligament)

quite limited and, according to Launois and Jamieson (33), in almost $40 \%$ of the cases, RIP is located in an anterior position, near the right edge of the cystic plate, leading to a quite small Sg 5 and the resected portion belonging predominantly to $8 \mathrm{~d}$.

The resection is difficult because it involves the approach of RIP which, usually, includes RHV although the later cannot be used systematically as a landmark for this plane $(1,46)$.

The surgery starts with the hilar step, isolating ASGP which, clamped, will isolate the RAS edges, with the right edge corresponding to RIP. AISP exposure is performed either by a hilar dissection of the $S 8 d+5 d$ GPs, or using the Sano-Makuuchi test (RHV and RHA clamping). The transection of the two resection planes will expose the RHV trajectory on the right, possibly AISV (V8i) on the left, and the S8d+5d sectioned GPs distally.

\section{Right dorsal subsectionectomy $(S 8 d+5 d)$, associated to a right posterior sectionectomy (Sg 6+7)}

This resection (figure 13 A-F) removes, practically, the RHV draining area i.e. the right suprahepatic sector; the intervention was described by Couinaud in 1957 (31), Kobayashi et al. (4) have been the first to perform this surgery, under the name of extended right posterior segmentectomy, in 10 cases of metastatic tumors in Sg 7, adjacent to RHV and where the imaging scans did not reveal an inferior right hepatic vein (IRHV) which would have allowed only the resection of Sg 7 and Sg 8 .

The surgery, as described in detail by the aforementioned authors, involves a right hemiliver 
mobilization along with an RHV isolation and sectioned. An extensive classic (intra-Glissonian) ASGP and PSGP vascular and biliary structures dissection is performed along with intercepting the later and the dehematization exposure of the right posterior section. To remove the entire RHV draining area, the authors traced AISP (the left edge of the resection plane) using a trajectory joining the left RHV edge at the top and the anterior sectional vein (ASV) stem (an ASGP indicator) distally. The parenchyma transection in the plane defined above shall intercept within the parenchyma the S8d+5d GPs, thus exposing the anterior side of the retro-hepatic IVC. This intervention may be performed using the extraGlissonian approach, thus simplifying the hilar step and isolating ASGP and PSGP while, for the later, the situation is facilitated by the presence of the Rouviere-Gans incisura in $2 \beta$ of the cases (18). Cho et al. for wide access to the ASGP tertiary GPs after isolating the later and PSGP, PSGP is ligatured, thus objectivizing RIP (6). The initial inferior hepatic side parenchyma transection to the left $(1.5-2 \mathrm{~cm})$ of this plane and towards the isolated ASGP allows for its wider approach. From this moment, AISP may be exposed either using the SanoMakuuchi maneuver (if RHV was not sectioned) or using the hilar access ligature of the S8d+5d GPs. The transection of the parenchyma separating the two RAS subsections ends at the right edge of MHV.

\section{Right posterior sectionectomy $(\mathrm{Sg} 6+7)$,}

extended to $\mathrm{Sg} 5$ and the dorsal subsegment 8 (8d)

This type of resection which, practically, maintains only the ventral subsegment $8(8 \mathrm{v})$ of the right hemiliver was proposed by some authors as an alternative to $\mathrm{RH}$ in the cases when such a surgery is not tolerated due to the altered liver function (11). According to Tanaka et al., an average volume of $155 \mathrm{ml}$ (11.4\%) of the THV may be preserved by maintaining $8 \mathrm{v}$ (14): The extra-Glissonian surgery involves a right hemiliver mobilization along with a RHV isolation and, at the hilum level, the RMGP, ASGP and PSGP isolation.

The RMGP clamping exposes the MHP (main portal fissure) opened to the HP level (and to the right MHV edge), followed by isolating, out of ASGP, the Sg5 GPs with a caudo-ventral trajectory and stemming from the ASGP stem or GP8v. Following the PSGP ligature, the parenchyma is sectioned transversally between the ischemic Sg5 and 8v, followed by isolating and clamping the S8d GPs that are to be later sectioned. Practically, the upper $2 \beta$ of AISP are exposed, and AISP is opened to the RHV level, to be later ligatured and resected. The SanoMakuuchi maneuver may be used to expose AISP, similar to the Tanaka et al technique (14).

\section{DISCUSSION}

As indicated above, RAS is the largest of the 4 hepatic sections, with $30 \%-41.2 \%$ of the THV volume $(1,13,66)$. Located in the center of the liver, around this section gravitates to the most difficult liver resections. Besides the liver tumor pathology, there is a recent interest in RAS in the field of living donor liver transplants, i.e. RAS harvesting along with the left hemiliver or alone, in some cases (67-68). Going back to tumor pathology, tumors localized in Sg 8 are quite frequent $(30 \%-40 \%$ of the cases), and this segment corresponds to an average $24 \%$ of the THV $(1,9,13)$. In his statistics Kishi et al. reveal that, from 966 cases of HCC subject to a liver resection, 154 cases $(15.94 \%)$ were subject to a $\mathrm{Sg} 8$ anatomic resection, while $122(12.62 \%)$ cases were subject to a non-anatomic resection. In HCC, where the intrahepatic neoplasm diffusion tends to spread to the portal system, the anatomic resection involves removing the affected portal area and, in case of liver pathology (cirrhosis), this oncology criterion should be conservative regarding the liver parenchyma, aiming to avoiding postoperative liver failure. The liver metastasis surgery (frequently involving colorectal metastases) uses, for reasons different from those related to HCC, non-anatomic resections but, in certain cases, anatomic resections are necessary and in such cases, depending on the tumor localization, the healthy parenchyma sacrificed might be unreasonably larger for the localization.

Practically, to avoid such unreasonable situations, a liver-sparing anatomic resection of the liver parenchyma is necessary both in HCC and the liver pathology related to it, and for some liver metastasis localizations. Due to its central position, some types of liver-sparing RAS anatomic resections were proposed, based on a revised segmentation of this area, aimed both at the portal and the suprahepatic distribution. Despite all the existing modern imaging progress, RAS segmentation is still under discussion and aims, primarily, at the Couinaud craniocaudal segmentation and the Hjortsjo segmentation, as updated by the Japanese authors as the ventrodorsal segmentation $(6-8,16,49,51,63)$. In practice, the main cause of discord is the fact that the Couinaud segmentation does not include an anatomic landmark between Sg 5 and Sg 8; a partially intersegmental (intermediate) vein between the two segments above named V8-V5i by Canhong Xiang and Makuuchi was identified during dissections by Kogure et al in only $7 \%$ of the cases $(16,69)$. The 
Hjortsjo-Kogure ventro-dorsal RAS segmentation, RAS divided vertically in 2 subsections (ventral and dorsal) by a portal plane named the anterior fissure $(\mathrm{AF})$, incorporating an anterior fissure or intermediate vein (AFV; $\mathrm{V} 8 \mathrm{i}$ ), present in $85 \%-100 \%$ of the cases $(1,6,10,14,49)$. It is worth mentioning that ASGP is located next to the hilum in the plane of this fissure. Another method for a RAS vertical bipartition is using the suprahepatic systematization described by Couinaud where the border between the right suprahepatic sector (RHV) and the median suprahepatic sector (MHV) consists of the right suprahepatic fissure (RSHF) that can be now objectivized using the Sano-Makuuchi test (52). According to Couinaud, a vertical division in 2 approximately equal areas using the suprahepatic systematization is possible in only $60 \%$ of the cases (32). We must emphasize that ASGP is located at hilum level in the RSHF plane, too $(31,32)$. The fact ASGP is located at hilum level in both that in the Hjortsjo-Kogure AF plane and the RSHF plane, thus becoming the common denominator both for the portal and the suprahepatic portal divisions leads to an anatomic "dilemma" contradicting Couinaud's scheme (a fissure includes either a portal pedicle, or a venous pedicle). This anatomic situation is similar to the one in the left intersectional plane (LIP, umbilical fissure) where this plane includes both the umbilical portion of the left vena porta and the umbilical fissure vein (behind the falciform ligament insertion point) and, in a postero-superior position, the terminal, almost vertical, portion of $\operatorname{LHV}(37,70)$.

For the aforementioned reasons and consistent with the Brisbane 2000 segmentation, we propose to replace the term "Hjortsjo-Kogure AF" with "anterior intersubsectional plane (AISP) and "AFV (V8i)" with "anterior right intersubsectional vein (AISV)". This way, AISP may be exposed either using a portal (ischemic) method, by clamping the relevant subsection GPs, or using the suprahepatic systematization with the Sano-Makuuchi test (where AISP corresponds to RSHF). We can thus avoid using the term "demarcation line" preferred by some authors, especially when using the venous occlusion test (Sano-Makuuchi). Although, according to some authors, the RAS portal ventro-dorsal vertical bipartition is present in $100 \%$ of the cases $(8,49)$, the universality of this concept is contested by some authors that the Couinaud segmentation is still current $(15,21)$.

The Kobayashi et al. study reveals that the ventrodorsal RAS bipartition was present in $23 \%$ of the cases, while the dominant Couinaud scheme was present in $53 \%$ of the subjects (15). The Kanecko et al. study emphasizes that these authors have used imaging to systematically identify the Couinaud in contrast to the less precise ventro-dorsal segmentation. Moreover, the AISV position (AFV, V8i) on the line between the two subsections (ventral and dorsal) is debatable (10).

A recent study by Cazauran et al., following their research on the PubMed literature research on articles about the RAS anatomy and surgery, revealed that the Couinaud cranio-caudal segmentation is the most frequent ( $50 \%-53 \%$ of the cases), followed by the ventro-dorsal segmentation (23\%$26 \%$ of the case). In the aforementioned study, AISV (AFV, V8i) may be used as a fixed landmark between the two subsections in only $63 \%$ of the cases (20). The study by Tanaka et al. produced similar results, revealing that AISV is located between the two subsections in only $46.7 \%$ of the cases (14).

The data described so far highlight the fact that the location of AISV in the resection plane of a RAS ventral or dorsal subsectionectomy is not absolute, especially when the plane was determined with the Sano-Makuuchi test. The classic hilar dissection access is one of the three portal pedicle accesses described by Couinaud in 1957 used frequently for $\mathrm{RH}$ or $\mathrm{LH}$. When performing a sectional or segmental resection, a classic dissection is difficult, dangerous or even impossible (30).

According to Makuuchi et al., the classic hilar dissection method of RAS resection is the most difficult liver resection (71). Moreover, performing a subsectionectomy or segmentectomy using this technique is, practically, impossible and, thus, the extra-Glissonian portal pedicle isolation was, according to Couinaud "a clear progress, considerably simplifying the sectionectomies and the segmentectomies" (30).

Couinaud described in 1985 the technique (suggested by him in 1957 already) of LMGP extraGlissonian and extra-hepatic isolation for a "simplified" LH (36).

Japanese authors Takasaki and Okamoto are responsible for the right hemiliver extra-Glissonian isolation of the major portal pedicles $(28,42,60,65)$.

However, for truth's sake, we must remember that the first right portal pedicle (RMGP) extraGlissonian isolation was performed by Couinaud in 1966 (72), for a partial vascular clamping in the right hemiliver, during a cholangioma Sg5 and Sg6 resection. In 1985 Couinaud and Desfemmes publish simplified right hepatectomy technique with primary RMGP isolation (73). The Laennec capsule, located 
between the HP and the liver, intra-hepatically and at hilum level, an anatomic detail Sugioka et al., as well as other authors emphasized in their works, allows for an extra-Glissonian and extra-hepatic major GP isolation (41). These authors proposed, based on this extra- and intra-hepatic Laennec capsule continuity, a standardization of the extraGlissonian resections, useful in the classic, laparoscopic and robotic surgery $(41,45)$.

The extra-Glissonian portal pedicle isolation is, in sectional and segmental surgery, a faster and much simpler alternative to a series of more or less sophisticated surgeries $(61,74-78)$; among those surgeries, the only one that stood the test of time is the Makuuchi technique, i.e. a sectionectomy/ segmentectomy using an ultrasound-guided puncture and injection of staining substance (indigo carmine) in the deep portal branches afferent to the target liver area (74). These techniques cannot provide an interception of all GPs in a segment and, in some cases, they consist of a subsegmentectomy, not of a Couinaud segmentectomy. According to Makuuchi et al., if the tumor is small and is irrigated by only one portal branch and the liver function is altered, the resected area may be $1 / 2$ or $2 / 3$ of a Couinaud segment (74).

The extra-Glissonian GP isolation (intra- or extrahepatic) has a series of anatomy, oncology and surgery advantages. The anatomic advantages are a double, i.e.:

- is avoided the vascular and biliary anatomic variations, frequent at the hilum level and located under HP and UP.

- also, the primary, sectional and segmental GPs, with some exceptions (Sg5, 7 and 8 GPs, as well and subsegment $4 a$ GPs originating in the superior UP side) are in a relatively superficial position $(1-2 \mathrm{~cm})$ from the inferior hepatic side and can, thus, be fairly easily superficialized. After a GP is isolated, its clamping will affect exclusively its dependent liver area, without impacting the afferent blood flow of a satellite area.

- from the oncology point of view, clamping the resected area GP at the very beginning of a surgery stops the tumor cells from becoming mobilized in the portal system following the liver mobilization and the parenchyma transection.

In the case of HCC, besides a series analyzed of prognostic factors (tumor and clinical characteristics, the importance of a peri-tumoral safety area, etc.), the prognostic importance of some surgical techniques was systematically neglected (79).

Tsuruta et al. were the first to demonstrate that the GP transection in the beginning of a surgery is an independent and strong prognostic indicator, preventing intra-operative metastasis formation and improving the post-operative survival rate of the HCC patients, and this was later confirmed by other authors, too $(2,3,5,14,79)$.

From a surgical point of view, the hilar access ASGP and tertiary GP isolation for a vertical bisectionectomy is quick and clamping this sectional GP will reveal from the very start the RAS limit, along with the two major intersectional planes. Sugioka et al. (41) have recently proposed, along the isolation of ASGP by a HP and cystic plate detachment, have recently proposed a single-process, cholecyst and cystic plate, dissection in the plane separating the later from the Laennec capsule (cystic plate cholecystectomy) for ASGP isolation (figure 1b). When using this technique, the dissection must be performed strictly in contact with the cystic plate, because intercepting the Laennec capsule may lead to unwelcome bleeding caused by sectioning the intensely vascularized fibrous elements that bind the capsule to the parenchyma, identified by Sabourin and named capsulo-Glissonian extensions by Couinaud (30).

In any case, ASGP isolation and the traction applied to it will allow, either directly, or by vertical hepatotomy, for exposing and ligaturing the tertiary GPs of the desired subsection, thus objectivizing AISP for a hepatic transection. Alternatively, AISP can be exposed using the venous-occlusive method (the Sano-Makuuchi test), and the plane thus obtained corresponds, actually, to the Couinaud RSHF.

Depending on the tumor localization and size, as well as on the liver damage level, there are a series of liver resections focused on the two RAS subsections that may lead to sparing parenchyma up to $22 \%-26 \%$ of THV (if compared to a classic resection for the same tumor localization) $(4,20)$.

\section{Conflict of interest}

The authors declare no potential conflicts of interests.

\section{REFERENCES}

1. Shindoh J, Mise Y, Shiochi S, Sugawara Y, Kokudo N. The intersegmental plane of the liver is not always flat - tricks for anatomical liver resection. Annals of Surgery, 2010, 251: 917-922; 
2. Yamamoto M, Takasaki $\mathrm{K}$, Ohtsubo $\mathrm{T}$, Katsuragawa $\mathrm{H}$, Fukuda $\mathrm{C}$, Katagiri S. Effectiveness of systematized hepatectomy with Glisson's pedicle transection at the hepatic hilus for small nodular hepatocellular carcinoma: retrospective analysis. Surgery 2001, 130:443-448

3. Giordano M, Lopez-Ben S, Codina-Barreras AC, Pardina B, Falgueras L, Torres-Bani S, Albiol M, Castro E, Figueras J. Extra-glissonian approach in liver resection. HBP (Oxford) 2010, 12(2): 94-100;

4. Kobayashi A, lamamura H, Miyagawa S, Shimada R, Makuuchi M, Kawasaki S. Extended right posterior segmentectomy for metastatic liver tumors. Surgery 1997, 121: 698-703;

5. Yamamoto M, Ariizumi S. Glissonian pedicle approach in liver surgery. Ann. gastroenterol. Surg. 2018, 2:124-128;

6. Cho A, Okazumi S, Miyazawa Y, Makino H, Miura F, Chiba S, Tohma T, Kudo H, Matsubara K, Ryu M, Ochiai T. Limited resection of the right hemiliver based on reclassification of the right anterior segment of the liver. Hepato-gastroenterology. 2004, 51:820-821

7. Cho A, Okazumi S, Miyazawa Y, Makino H, Miura F, Ohira G, Yoshinaga Y, Tohma T, Kudo H, Matsubara K, Ryu M, Ochiai T. Limited resection based on reclassification of segment 8 of the liver. Hepato-gastroenterology. 2004, 51:575-576;

8. Ryu M, Cho A. Editors. New liver anatomy: portal segmentation and the drainage vein. Editura Springer 2009;

9. Kishi $\mathrm{Y}$, Hasegawa K, Kaneko J, Aoki T, Beck $\mathrm{Y}$, Sugawara $\mathrm{Y}$, Makuuchi M, Kokudo N. Resection of segment VIII for hepatocellular carcinoma. Br J Surg. 2012, 99:1105-1112;

10. Kaneko T, Tomyiama T, Kiyuna H, Machida T et al. Identification of Ryu's segmentation of the liver using MDCT analysis. J.Nippon Med. Sch. 2010, 77: 244-249;

11. Fujimoto J, Hai S, limuro Y. Anatomic liver resection of right paramedian sector: ventral and dorsal resection. J. Hepatobiliary Pancreat Sci 2015, 22: 538-545

12. Kurimoto $\mathrm{A}$, Yamanaka $\mathrm{J}$, Hai $\mathrm{S}$, Kondo $\mathrm{Y}$, Sueoka $\mathrm{H}$ et al. Parenchyma-preserving hepatectomy based on portal ramification a perfusion of the right anterior section: preserving the ventral or dorsal area. J. Hepatobiliary Pancreat Sci 2016, 23: 158-166;

13. Tani K, Shindoh J, Akamatsu N, Arita J, Kaneco J et al. Venous drainage map of the liver for the complex hepatobiliary surgery and liver transplantation. HPB 2016, 18:1031-1038;

14. Tanaka K, Matsumoto $\mathrm{C}$, Takakura $\mathrm{H}$, Matsuo $\mathrm{K}$, Nagano $\mathrm{Y}$, Endo I, Togo S, Shimada H, Bourquain H, Peitgen HO.Technique of right hemihepatectomy preserving ventral right anterior section guided by area of hepatic venous drainage. Surgery. 2010,147(3): 450-8.

15. Kobayashi T, Ebata T, Yokohama $Y$, Igami $T$, Sugawara $G$ et al. Study on the segmentation of the right anterior sector of the liver. Surgery 2017, 161: 1536-1542;

16. Kogure K, Kuwano H, Fujimaki N, Ishikawa H, Takada K. Reproposal for Hjortsjo's segmental anatomy on the anterior segment in human liver. Arch Surg. 2002, 137:1118-1124;

17. Câmpeanu I, Petrescu R, Dragan C, Pruna M, Corneci D, Buia F, Zeca I. Rezectie (supra)hepatica sinistromediana. 0 reactualizare a segmentatiei hepatice a lui Hjortsjo. Chirugia 2005, 100: 349-356;

18. Câmpeanu I. Rezectiile hepatice extraglissoniene. Editura Celsius 2017;

19. Kondo S, Katoh H, Hirano S, Ambo Y, Takana E, Saito K, Noji T, Okushiba S, Morikawa T, Taira K. Hishiyama $\mathrm{H}$. Venous drainageguided selective hepatectomy: a novel approach to liver surgery. Hepato-Gastroenterology, 2004, 51:1-3;

20. Cazauran J-P, Paris L, Rousset P, Mercier F, Kapenekian V et al. Anatomy of the right anterior sector of theliver and its clinical implications in surgery. J Gastroint, Surg. 2018, 10: 1819-1831;

21. Sato $S$. Boundary between the drainage areas of the middle and right hepatic vein. Liver Cancer 2017, 6: 146-160;

22. Taniai N, Machida T, Yoshida H, Kawano Y et al. Role of the anterior fissure vein in ventral or dorsal resection at Segment 8 of liver European Journal of Surg Oncol 2018, 44: 664-669;

23. Katagiri S, Ariizumi SI, Kotera $Y$ et al. Right hepatectomy using Glissonean pedicle transection method with anterior approach. J Hepatobiliary Pancreat Sci 2012, 19: 25-29;

24. Strasberg S. Terminology of liver anatomy and liver resections: coming to grips with hepatic babel. J Am Coll Surg 1997, 184: 413-433

25. Belghiti J, Clavien PA, Gadzijev E, Garden JO, Lay WY, Makuuchi M,
Strong RW. The Brisbane 2000 Terminology of Liver Anatomy and Resections. HBP 2000, 2: 333-339;

26. Belghiti J. L'anatomie du foie peut-elle changer ? Annales de chirurgie 2002, 127:416-417;

27. Takasaki K. Glissonean Pedicle transection method for hepatic resection. Editura Spirnger 2007;

28. Takasaki K, Glissonean pedicle transection method for hepatic resection: a new concept of liver segmentation. J Hepatobiliary Pancreat Surg. 1998, 5:286-291;

29. Takasaki K, Kobayashi S, Tanaka S, Saito A, Yamamoto M, Hanyu F. Highly anatomically systematized hepatic resection with Glissonean sheath code transection at the hepatic hilus. Int Surg. 1990, 75: 73-77;

30. Couinaud C. Surgical anatomy of the liver revisited. Paris 1989;

31. Couinaud C. Le Foie. Etudes anatomiques et chirurgicales. Editura Masson 1957;

32. Couinaud C. Controlled hepatectomies and exposure of the intrahepatic bile ducts: anatomical and technical study. Paris 1981;

33. Launois B, Jamieson GG. Modern operative techniques in liver surgery. Editura Churchill Livingstone 1993;

34. Launois B, Jamieson GG. The importance of Glisson's capsule and its sheaths in the intrahepatic approach to resection of the liver. Surg Gynecol Obstet. 1992, 174:7-10;

35. Launois B, Jamieson GG. The posterior intrahepatic approach in liver surgery. Editura Springer Landes 2013;

36. Couinaud C. A simplified method for controlled left hepatectomy, Surgery 1985, 97:358-361;

37. Bismuth $\mathrm{H}$. Surgical anatomy and anatomical surgery of the liver. World J. Surg 1982, 6:3-9

38. Tung TT. Les resections majeures et mineures du foie. Editura Masson, 1979:

39. Yamamoto M, Katagiri S, Ariizumi SI, Kotera $\mathrm{Y}$, Takahashi $\mathrm{Y}$. Glissonean pedicle transection method for liver surgery. J Hepatobiliary Pancreat Sci. 2012, 19: 3-8;

40. Yamamoto M, Katagiri S, Ariizumi SI, Kotera Y, Takahashi Y, Egawa $\mathrm{H}$. Tips for anatomical hepatectomy for hepatocellular carcinoma by the glissonean pedicle approach. J Hepatobiliary Pancreat Sci 2014, 21: E53-E56;

41. Sugioka A, KatoY, Tanahashi Y. Systematic extrahepatic Glissonean pedicle isolation for anatomical liver resection based on Laennec's capsule: proposal of a novel comprehensive surgical anatomy of the liver. J Hepatobiliary Pancreat Sci 2017, 24:17-23

42. Takasaki K, Sobayashi S, Tanaka S, Muto H, Watayo T. Highly selected hepatic resection by glisson sheath-binding method. Digestive Surgery 1986, 3: 121 (abstract).

43. Kawarada Y, Das BC, Taoka H, Anatomy of the hepatic hilar area: the plate system. J Hepatobiliary Pancreat Surg 2000, 7:580-586;

44. Yu HC, Jin ZW, Jin GY, You $\mathrm{H}$ et al. Identification of the anterior sectoral trunk with particular reference to the hepatic hilar plate and its clinical importance. Surgery 2001, 149: 291-296;

45. Hu Y, Shi J, Wang S, Zhang W, Sun X et al. Laennec's approach for laparoscopic anatomic hepatectomy based on Laennec's capsule. BMC Gastroenterology 2019, 194: 1107-9;

46. Van Leeuwen M, Noordzij J, Fernandes MA, Hennipman A, Feldberg $\mathrm{M}$, Dillon E. Portal venous and segmental anatomy of the right hemiliver: observations based on three-dimensional spiral CT renderings. Am J Roentgnol 1994, 163: 1395-1404;

47. Ammar H, Azzaza M, Gupta R, Abdessayed N, Faidi B, Nefis A-N, Abdelkefi S, Morjane A. Identification landmark for right anterior portal pedicle: "the zone of $2 \mathrm{~cm}$ ". Surg Radiol Anat (2017) 39:711-715;

48. Surjan R.C.T, Makdissi F.F, MachadoM.A.C. Anatomical basis for the intrahepatic glissonisn approach during hepatectomies. Arg Bras Cir Dig 2015, 28(2): 128-131;

49. Cho A, Okazumi S, Makino H, Miura F, Shuto K, Mochiduki R, Tohma T, Kudo H, Matsubara K, Gunji H, Yamamoto H, Ryu M, Ochiai T. Anterior fissure of the right liver-the third door of the liver. J Hepatobiliary Pancreat Surg. 2004, 11:390-396;

50. Hjortsjo $\mathrm{CH}$. The topography of the intraheppatic duct systems. Acta Anatomica 1951, vol XI, Fasc 4: 599-615;

51. Kanemura E, Togo S, Shizawa R, Tanaka K, Shimada H. Subdivision 
of liver anterior segment into two units according to hepatic venous drainage. Hepato-gastroenterology. 2000, 47:1056-1059;

52. Sano K, Makuuchi M, Miki K, Maema A, Sugawara Y, Imamura H, Matsunami H, Takayama T. Evaluation of hepatic venous congestion: proposed indication criteria for hepatic vein reconstruction. Ann.Surg 2002, 236: 241-247;

53. Murata S, Itai Y, Asato M, Kobayashi H, Nakajima K, Eguchi N et al. Effect of temporary occlusion of the hepatic vein on dual blood in the liver: evaluation with spiral CT. Radiology 1995, 197: 351-356;

54. Hepp J, Couinaud C. L'abord et l'utilisation du canal hepatique gauche dans les reparations de la voie biliaire principale. La Presse Medicale 1956, 64: 947-948;

55. Strasberg SM, Linehan DC, Hawkins WG. Isolation of right main and right sectional portal pedicles for liver resection without hepatotomy or inflow occlusion. The American College of Surgery 2008, 206:390-396;

56. Regimbeau J M, Mauvais F. L' abord glissonien pour les resections hepatiques. Journal Chirurgie (Paris) 2008, 145: 355 - 362;

57. Machado MAC, Herman P, Machado MCC. A Standardized technique for right segmental liver resections. Arch. Surg. 2003 138:918-920;

58. Batignani G. Hilar plate detachment and extraglissonian extrahepatic anterior approach to the right portal pedicle for right liver resections. J Am Coll Surg 2000, 190:631-634;

59. Mouly C, Fuks D, Browet F, Mauvais F, Potier A, Yzet T et al. Feasibility of the glissonian approach during right hepatectomy. HPB 2013, 15: 638-645

60. Okamoto N, Yamanaka N: Anatomical resection of the right hepatic subsegments preceded by suprahilar ligation of the portal pedicles. Tobe T et al editors. Primary Liver Cancer in Japan Tokyo, SpringerVerlag 1992, 229-233;

61. Curro G, Bartolotta M, Barbera A, Jiao L, Habib N, Navarra G. Ultrasound-guided radiofrequency-assisted segmental liver resection - a new technique. Annals of Surgery 2009, 250: 229-233;

62. Galperin El, Karagiulian SR. A new simplified method of selective exposure of hepatic pedicles for controlled hepatectomies. HPB Surg. 1989;1(2):119-30.

63. Cho A, Okazumi S, Takayama W, Takeda A, Iwasaki K, Sasagawa S Natsume T, Kono T, Kondo S, Ochiai T, Ryu M. Anatomy of the right anterosuperior area (segment 8) of the liver: evaluation with helical CT during arterial portography. Radiology 2000, 214:491-495;

64. Lee JH, Jin GY, Jin ZW, Yu HC, Cho BH. Ramification of Glisson's sheath peripheral branches and clinical implications in the era of local ablation therapy. Surg Radiol Anat. 2010, 32:911-917;

65. Okamoto E, Yamanaka N, Toyosaka A, Nobutaka T, Kohei Y. Current status of hepatic resection in the treatment of hepatocellular carcinoma. Okuda K, Ishak KG editors. Neoplasm of the Liver. New York, Springer-Verlag 1987, 353-365;

66. Suh KS, Suh SW, Lee JM, Choi YR et al. Living donor liver transplantation using a left liver extended to right anterior sector. Transplant international 2015, 28: 765-769;

67. Suh KS, Kim HS, Yin J et al. Living donor liver transplantation using a right anterior section of the liver. Liver transpl. 2017, 23: 1077-80;

68. Navarro JG, Choi GH, Kim MS. Right anterior section graft for living donor liver transplantation. Medicine 2019, 98: 19 (e15212);

69. Xiang C, Liu Z, Dong J, Sano K, Makuuchi M. Precise anatomical resection of the ventral part of Segment VIII. Int J Surg Case Rep 2014, 5(12): 924-6;

70. Botero AC, Strasberg SM. Division of the left hemiliver in man segments, sectors or sections. Liver Transplantation and Surgery 1998, 4: 226-231;

71. Makuuchi M, Hashikura Y, Kawasaki S, Tan D, Kosuge T, Takayama T. Personal experience of right anterior segmentectomy (segments V and VIII) for hepatic malignancies. Surgery 1993, 114: 52-58;

72. Couinaud C. Plaidoyer pour une segmentation hepatique exacte et une technique anatomique de resection reglee du foie . Le clampage partiel du pedicule hepatique. La Presse Medicale 1966, 74: 28492852;

73. Couinaud C, Desfemmes FN. Hepatoma in Addition to Active Viral Hepatitis. A Simplified Technic of Right Hepatectomy in the Variety With a Long Portal Pedicle. Zinc in Hepatectomies. Apropos of a Case. Chirurgie. 1985;111(7):599-604. French

74. Makuuchi M, Hasegawa $\mathrm{H}$, Yamazaki S. Ultrasonically guided subsegmentectomy. Surg Gynec Obst 1985, 161: 346-350;

75. Shimamura Y, Gunven P, Takanaka Y, Shimizu H, Akimoto H, Shima Y, Arima K, Takahashi A, Kitya T, Matsuyama T, Hasegawa $\mathrm{H}$. Selective portal branch occlusion by balloon catheter during liver resection. Surgery 1986, 100: 938-941;

76. Ou JR, Chen W, Lau WY. A New Technique of hepatic segmentectomy by selective portal venous occlusion using a balloon catheter through a branch of the superior mesenteric vein. World J Surg 2007, 31: 1240-1242;

77. Torzilli G, Procopio F, Palmisano A, Donadon M, Del Fabbro D, Marconi M, Scifo G, Montorsi M. Total or partial anatomical resection of segment 8 using the ultrasound-guided finger compression technique. HBP (Oxford) 2011, 13: 586-591;

78. Torzilli G, Procopio F, Palmisano A, Donadon M et al. Total or partial anatomical resection of segment 8 using the ultrasound-guided finger compression technique. HPB 2011, 13: 586-591;

79. Tsuruta K, Okamoto A, Toi M, Saji H, Takahashi T. Impact of selective Glisson transection on survival of hepatocellular carcinoma. Hepato-gastroenterology 2002, 49:1607-1610; 